\title{
Non-destructive approaches for assessing biofouling of household reverse osmosis membranes
}

\section{Authors: Stephan D. Markwardt, Nirmala Ronnie, and Anne K. Camper}

This is an Accepted Manuscript of an article published in Biofouling on September 2018, available online: http://www.tandfonline.com/10.1080/08927014.2018.1493106.

Markwardt, Stephan D., Nirmala Ronnie, and Anne K. Camper, "Non-destructive approaches for assessing biofouling of household reverse osmosis membranes," Biofouling, September 2018, 34(7): 740-752. doi: 10.1080/08927014.2018.1493106 


\title{
Non-destructive approaches for assessing biofouling of household reverse osmosis membranes
}

\author{
Stephen D. Markwardt ${ }^{a}$, Nirmala Ronnie ${ }^{b}$ and Anne K. Camper ${ }^{a, c}$ \\ ${ }^{a}$ Center for Biofilm Engineering, Montana State University, Bozeman, MT, USA; ${ }^{\mathrm{b}}$ Safety and Environmental Assurance Centre, Unilever \\ R\&D, Bangalore, India; 'Department of Civil Engineering, Montana State University, Bozeman, MT, USA
}

\begin{abstract}
This study determined economic non-destructive methods to assess biofouling in point of use reverse osmosis (RO) membrane treatment systems. Three parallel household RO membrane units were operated under controlled feed water conditions to promote biofouling, inorganic fouling and a combination of both. Operational and biological parameters were monitored throughout the systems' lifespan. Membrane autopsies assessed the degree and type of fouling. Statistical models determined statistically relevant parameters for fouling types that were validated with membrane autopsies. Permeate flow rates decreased differently with biofouling vs inorganic fouling. Large increases in permeate conductivity were noted in membranes suffering from biofouling and not in inorganically fouled membranes. The concentration of cell clumps from detached biofilm in the retentate increased in membranes experiencing biofouling and no increase was seen for inorganically fouled membranes. A combination of these methods could be used to conveniently assess the types of fouling experienced by RO systems.
\end{abstract}

\section{Introduction}

A significant problem with reverse osmosis (RO) water treatment is membrane fouling. Fouling is the accumulation of foreign materials from the feed water on the active membrane surface and/or on the feed channel spacer to the point of causing operational problems (Pandey et al. 2012). Fouling of membranes results in increased power consumption and a reduction of membrane lifespan, which are major operational and economic issues for the feasibility of membrane treatment (Kavanagh et al. 2009). Inorganic fouling can occur from the precipitation of dissolved solids on the membrane surface (inorganic fouling) or the accumulation of inert particles (colloidal fouling) (Pandey et al. 2012). Organic fouling is the deposition of non-viable organic matter on the membrane surface (Al-Juboori and Yusaf 2012), and includes humic substances, amino acids, sugars and aromatic acids (Pandey et al. 2012). Biofouling is the attachment and growth of microorganisms to form a biofilm on the membrane surface and/or feed channel spacer to the point where economic operation is impacted (Flemming 1997; Vrouwenvelder and van der Kooij 2001; Pandey et al. 2012). Of all the fouling types, biofouling is the most detrimental to long term operation (Pandey et al. 2012), contributing to $>45 \%$ of all membrane fouling (Komlenic 2010).

Ideally, membrane system operators need tools to assess the degree and type of membrane fouling to run the system efficiently, predict time to membrane failure or the need for cleaning, and to apply effective membrane cleaning techniques. Non-destructive methods such as pressure drop and fluid flux across the membrane have been used to monitor fouling and destructive membrane autopsies have been used to determine the type and extent of membrane fouling. One traditional practice for monitoring membrane fouling is based on the increase in transmembrane pressure (TMP) at a constant flux. However, this method is not sensitive enough to detect the onset of membrane fouling since fouling is usually well established before a change in TMP can be detected (Sim et al. 2013). Furthermore, studies have shown that only the feed channel pressure drop (FCP) as measured with accurate differential pressure transmitters is affected by the formation of a biofilm, making TMP useless for detecting this type of fouling (Vrouwenvelder et al. 2011a). Additionally, high concentrations of inorganics may also contribute to increased FCP drop so it is not totally indicative of 
biofouling (Vrouwenvelder et al. 2011a). Since the 1960s RO membrane fouling has been indicated or measured on-line by a flux decline (Tay and Song 2005; Kavanagh et al. 2009). Unfortunately, this method, while non-destructive, cannot be used to elicit the type of fouling, nor is it predictive because fouling is usually well established before a decline in flux can be detected (Sim et al. 2013).

Membrane autopsies are a precise and accurate way of determining the type of fouling on a membrane surface. In Flemming (1997), a standard procedure to perform an autopsy was described using representative swatches that can be analyzed by many methods (Al-Juboori and Yusaf 2012). Huang et al. (2013) used confocal microscopy and live/dead staining to verify biofouling on desalination $\mathrm{RO}$ membranes. While autopsies determine the extent and type of fouling and are extremely useful laboratory tools to validate potential non-destructive methods to assess fouling (Al-Juboori and Yusaf 2012), they are retrospective and not economic for plant operations.

Noting the limitations of the above methods, there is a need for non-destructive approaches to determine the type and extent of membrane biofouling so that action can be taken to prevent irreversible damage. Several approaches to this have been investigated, including feed water assays, including assimilable organic carbon (Vrouwenvelder and van der Kooij 2001; Vrouwenvelder et al. 2011b) and biofilm formation rate (Vrouwenvelder and van der Kooij 2001; Vrouwenvelder et al. 2011a, 2011b); the use of membrane fouling simulators (Vrouwenvelder et al. 2011a, 2011b), measuring specific oxygen consumption rate to equate oxygen consumption to biomass (Kappelhof et al. 2003; Farhat et al. 2015), counting bacterial cells in retentate water using flow cytometry (Dixon et al. 2012), applying a fluorescence spectrum-based assessment to analyze for organism-produced extracellular polymeric substances (EPS) in the retentate (Hwang et al. 2012), using electrical impedance spectroscopy where shifts in potential across the membrane surface are measured (Kavanagh et al. 2009; Sim et al. 2013), employing surface-enhanced Raman spectroscopy in a simulator (Kögler et al. 2016), the use of optical coherence tomography for imaging feed spacer fouling (West et al. 2016) and imaging membrane surfaces with nuclear magnetic resonance microscopy to detect biofouling (Graf von der Schulenburg et al. 2008; Pintelon et al. 2010; Vrouwenvelder et al. 2011a; van Loosdrecht et al., 2012; Fridjonsson et al. 2015). These methods show promise, but most are suited for large RO plants with laboratories that contain sophisticated instruments. The industry still needs economic, easily validated methods suitable for both large and small systems so that RO membrane design and operation can be advanced. This is critical for household units that treat questionable water sources for potable use, since fouling and subsequent loss of membrane integrity may contribute to pathogen breakthrough, especially viruses (Mia et al. 2004; Antony et al. 2012).

Using household RO units, this laboratory-based project examined options for detecting and predicting biofouling. Easily collected water samples (feed water, retentate, permeate) were analyzed along with operational data and those results compared to membrane autopsy information. The outcome was an assessment of the value of a combination of methods to predict biofouling before system failure.

\section{Materials and methods}

\section{Experimental design}

The experimental system was designed to simulate intermittent home use conditions. The goal was to generate 101 of permeate water per day per reverse osmosis line. An operational time of $14 \mathrm{~min}$ created 3.31 of permeate; running the system three times a day at 8 -h intervals resulted in the targeted permeate water production. Reactors operated at constant flux until maximum booster pump head was achieved, then the system switched to constant pressure mode.

Feed solution concentrations were chosen to provide accelerated fouling. Targeted feed concentrations were (1) $10 \mathrm{mgl}^{-1}$ of total organic carbon and $500 \mathrm{mgl}^{-1}$ total inorganics to encourage both inorganic fouling and biofouling, (2) $10 \mathrm{mgl}^{-1}$ of total organic carbon and $150 \mathrm{mgl}^{-1}$ of inorganics (background in feed makeup water) to promote biofouling and (3) $0 \mathrm{mgl}^{-1}$ of added total organic carbon and $500 \mathrm{mgl}^{-1}$ of total inorganics to favor inorganic fouling (Table 1). Organic carbon was comprised of equimolar concentrations (in terms of $\mathrm{C}$ ) of the first eight compounds in Table 1 . In Phase $1,2 \mathrm{mgl}^{-1}$ of organic carbon and $500 \mathrm{mgl}^{-1}$ of inorganics were used initially but because a significant reduction in performance was not detected by day 49 the organic carbon concentration was raised to $10 \mathrm{mgl}^{-1}$. This level was used throughout the rest of the experiments.

In Phases 1 and 4, membranes were operated until failure, defined as total dissolved solids (TDS) removal $<75 \%$ and/or an $\sim 50 \%$ reduction in permeate flow. Dual failure criteria were needed since inorganically loaded membranes maintained a high TDS removal $(>95 \%)$ even with significantly diminished 
permeate production (50\%). For Phases 2 and 3, parallel reactors were sacrificed at milestones of $1 / 3$ and $2 / 3$ of the predicted maximum increase in transmembrane pressure and upon failure.

\section{Reactors}

The experimental system (Figure 1) consisted of three parallel household reverse osmosis units, feed tanks and common dose tanks. All pumps were controlled by the Control Company's Traceable ${ }^{\circledR}$ Outlet Controllers (Control Company, Cat \# 5090, Friendswood, Texas, USA) and were calibrated bimonthly.

A reverse osmosis unit consisted of a 75 GPD reverse osmosis membrane (DOW Filmtec, Cat \# TW30-1812-75, Minneapolis, MN, USA), membrane housing, tubing and a $450 \mathrm{ml} \mathrm{min}^{-1}$ flow restrictor. Liquid-filled pressure gauges (McMaster-Carr, Cat \#

Table 1. An overview of the experimental feed water properties and concentrations by experimental phase.

\begin{tabular}{|c|c|c|c|c|}
\hline Constituent & $\begin{array}{l}\text { Phase I before } \\
\text { day } 49 \text { [ppm] }\end{array}$ & $\begin{array}{l}\text { Phase I post day } 49 \text { and } \\
\text { phase IV combined [ppm] }\end{array}$ & $\begin{array}{c}\text { Phase II and phase IV } \\
\text { organics }\left[\mathrm{g} \mathrm{I}^{-1}\right]\end{array}$ & $\begin{array}{l}\text { Phase III and phase IV } \\
\text { inorganics }[\mathrm{g}] \mathrm{I}^{-1}\end{array}$ \\
\hline L-Glutamic acid & 0.613 & 3.063 & 3.063 & - \\
\hline L-Aspartic acid & 0.693 & 3.463 & 3.463 & - \\
\hline L-Serine & 0.729 & 3.646 & 3.646 & - \\
\hline L-Alanine & 0.618 & 3.091 & 3.091 & - \\
\hline $\mathrm{D}(+)$ Glucose & 0.625 & 3.125 & 3.125 & - \\
\hline D(-)Galacturonic acid monohydrate & 0.736 & 3.680 & 3.680 & - \\
\hline $\mathrm{D}(+)$ Galactose & 0.625 & 3.125 & 3.125 & - \\
\hline D(-)Arabinose & 0.625 & 3.125 & 3.125 & - \\
\hline Monobasic potassium phosphate & 0.227 & 1.133 & 1.133 & - \\
\hline $\mathrm{CaCl}_{2}$ & 74.703 & 74.703 & - & 74.703 \\
\hline $\mathrm{MgCl}_{2} * 6 \mathrm{H}_{2} \mathrm{O}$ & 43.672 & 43.672 & - & 43.672 \\
\hline $\mathrm{Al}_{2}\left(\mathrm{SO}_{4}\right)_{3} * 16 \mathrm{H}_{2} \mathrm{O}$ & 1.464 & 1.464 & - & 1.464 \\
\hline $\mathrm{Na}_{2} \mathrm{SO}_{4}$ & 20.195 & 20.195 & - & 20.195 \\
\hline $\mathrm{MgSO}_{4} * 7 \mathrm{H}_{2} \mathrm{O}$ & 30.040 & 30.040 & - & 30.040 \\
\hline $\mathrm{NaHCO}_{3}$ & 218.611 & 218.611 & - & 218.611 \\
\hline $\mathrm{MnSO}_{4}{ }^{*} \mathrm{H}_{2} \mathrm{O}$ & 0.157 & 0.157 & - & 0.157 \\
\hline Background TDS & 150 & 150 & 150 & 150 \\
\hline $\mathrm{pH}$ & $7.80-7.88$ & $7.80-7.88$ & $7.41-8.14$ & $8.20-8.32$ \\
\hline
\end{tabular}

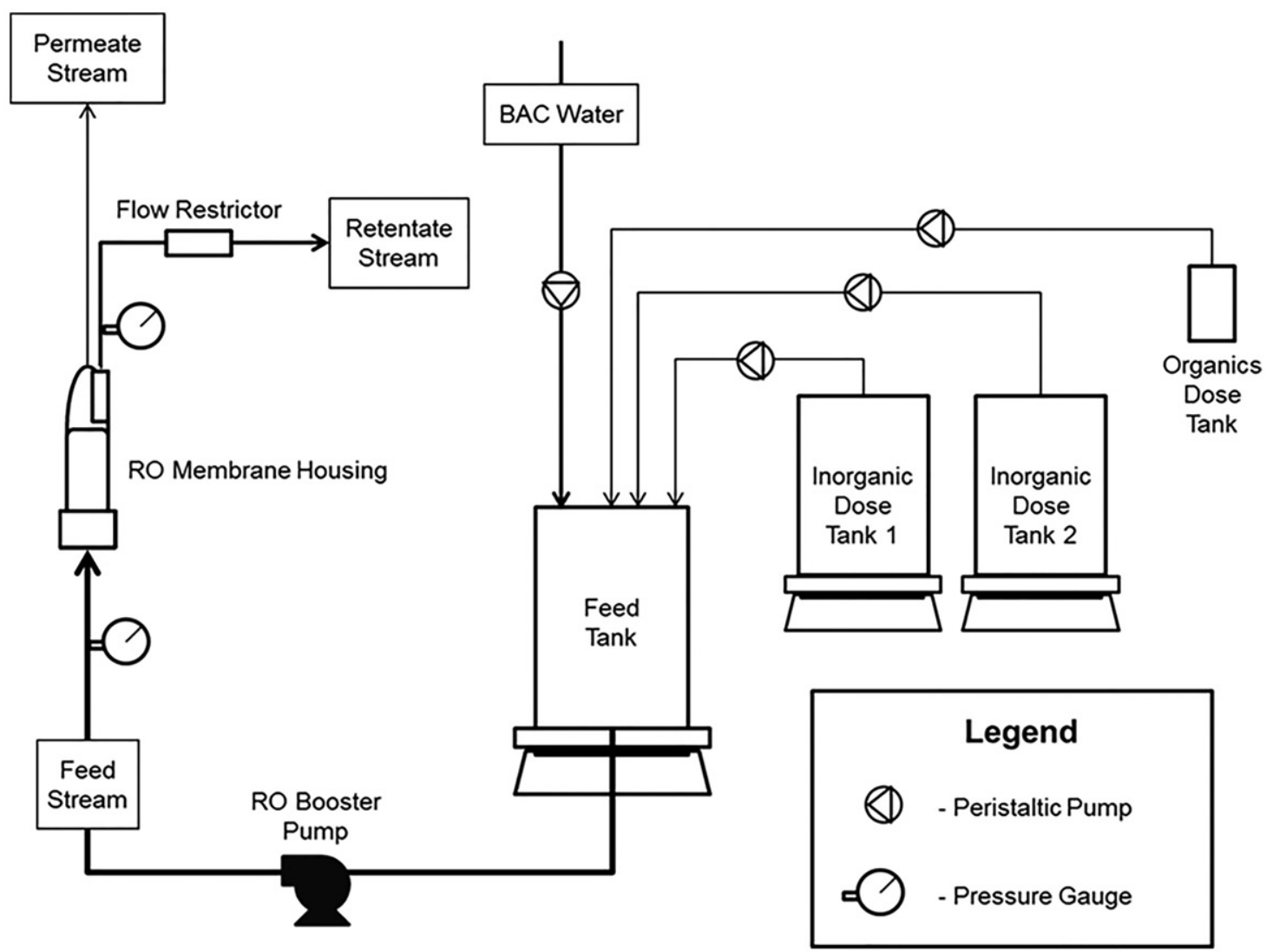

Figure 1. Process schematic for one of the three parallel RO membrane lines. The same dose tanks were used by all three lines. 
3708K21, Santa Fe Springs, CA, USA) were used in conjunction with $0.02 \mathrm{~cm}$ orifice diameter pulsationdampening snubbers (McMaster-Carr, Cat \# 3820K27, Santa Fe Springs, CA, USA) to measure feed and retentate stream pressures. A RO booster pump (SHURflo, Cat \# 8075-142-313, Costa Mesa, CA, USA) was employed so the system operated at desired pressures.

The feed tanks were 151 Nalgene wide mouthed carboys plumbed to contain 13.81 of feed solution and were continually mixed using magnetic stir plates (Barnstead/Thermolyne, Cat \# 846725, Dubuque, IA, USA). Peristaltic pumps pulled water from a reservoir continuously fed by Bozeman (MT, USA) tap water which had passed through a granular activated carbon (GAC) column and a biologically activated carbon (BAC) column to remove background chlorine and organic carbon from the tap water (BAC water) and served as a source of indigenous bacteria for the colonization of the membranes. The BAC water had a background TDS concentration of $150 \mathrm{mgl}^{-1}$ and $\sim 1 \mathrm{mgl}^{-1}$ of total organic carbon. The feed tanks and all transparent tubing were covered to prevent the growth of photosynthetic organisms. Tubing was replaced between experiments and the tank was routinely cleaned.

Each feed tank, filled with BAC water, was dosed with stock solutions to obtain the desired influent conditions (organics and/or inorganics) via calibrated peristaltic pumps. Dosing stopped $4 \mathrm{~min}$ prior to each membrane run to ensure uniform dispersion of the dosed solutions. The stock solutions were replaced biweekly after the tank and lines were rinsed and autoclaved.

\section{Sampling}

Operational parameters and analyses for each of the phases are shown in Table 2.
Pressure and flow were measured daily. Pressure was read to the nearest $3.45 \times 10^{4} \mathrm{~Pa}$ and was normalized to the initial observed pressure drops. Transmembrane pressure was the drop of pressure from the feed to the permeate line and feed channel pressure drop was the pressure drop between the feed and retentate lines. Permeate and retentate flows were measured using a stopwatch and a graduated cylinder. Permeate flow data were normalized by taking the ratio of the current measurement to the initial measurement $\left(\mathrm{F}_{\mathrm{t}} / \mathrm{F}_{0}\right)$.

Retentate and permeate samples were collected during the morning run in sterile test tubes directly from the outlets of their respective lines after $2 \mathrm{~min}$ of system operation to flush stagnant water from the lines. Samples from the feed tanks were collected via pipette and placed in sterile test tubes. Samples were then stored at $4{ }^{\circ} \mathrm{C}$ until relevant analyses could be performed.

In Phase 1 and 4, all membranes were autopsied upon membrane failure. In Phases 2 and 3 membrane autopsies were performed when a membrane replicate achieved a set parameter milestone of $1 / 3$ and $2 / 3$ of the predicted maximum increase in trans-membrane pressure and at membrane failure. Maximum increase of trans-membrane pressure was predicted by subtracting the initial trans-membrane pressure from the maximum pressure of the $\mathrm{RO}$ booster pump. Membrane assays used swatch sizes of $36 \mathrm{~cm}^{2}$ at three sample locations for a total of $108 \mathrm{~cm}^{2}$, producing results for $2.2 \%$ of the active membrane surface since the membranes had an active surface area (area where flux was possible) of $4,800 \mathrm{~cm}^{2}$. To obtain swatches, membranes were carefully cut open and unrolled and swatches removed with a sterile scalpel. Swatches were transferred to sterile Petri dishes with sterile forceps, $10 \mathrm{ml}$ of autoclaved nano-pure water were added, the surface scraped with a sterile policeman,

Table 2. Operational analyses performed based on phase and sample location.

\begin{tabular}{|c|c|c|c|}
\hline Phase & Feed loading & Process stream & Operational analyses \\
\hline \multirow[t]{3}{*}{ Phase I } & $\begin{array}{r}10 \mathrm{ppm} \text { organics } \\
500 \mathrm{ppm} \text { inorganics }\end{array}$ & Feed & Pressure, ATP, HPC, direct counts, TOC, conductivity \\
\hline & & Retentate & Pressure, flow, ATP, HPC, direct counts, cell clumping, TOC, conductivity \\
\hline & & Permeate & Flow, ATP, HPC, conductivity \\
\hline \multirow[t]{3}{*}{ Phase II } & $\begin{array}{r}10 \mathrm{ppm} \text { organics } \\
150 \mathrm{ppm} \text { inorganics }\end{array}$ & Feed & Pressure, ATP, HPC, direct counts, TOC, conductivity, pH, temperature \\
\hline & & Retentate & Pressure, flow, ATP, HPC, direct counts, cell clumping, TOC, conductivity, concentrated protein \\
\hline & & Permeate & Flow, ATP, HPC, TOC, conductivity \\
\hline \multirow[t]{3}{*}{ Phase III } & $\begin{array}{r}0 \mathrm{ppm} \text { organics } \\
500 \mathrm{ppm} \text { inorganics }\end{array}$ & Feed & Pressure, ATP, HPC, direct counts, TOC, conductivity, $\mathrm{pH}$, temperature \\
\hline & & Retentate & Pressure, flow, ATP, HPC, direct counts, cell clumping, TOC, conductivity \\
\hline & & Permeate & Flow, ATP, HPC, TOC, conductivity \\
\hline \multirow[t]{2}{*}{ Phase IV } & 1 replicate of each & Feed & Pressure, ATP, HPC, direct counts, conductivity, pH, temperature \\
\hline & & Retentate & Pressure, Flow, ATP, HPC, direct counts, cell clumping, conductivity, hydrogen sulfide \\
\hline
\end{tabular}


rinsed with the same water and the sample water transferred to a sterile sample vial. Sample vials were vortexed with a Vortex-Genie 2 (Scientific Industries, Model \# G-560, Bohemia, NY, USA) intermittently for $30 \mathrm{~s}$ at speed setting 9. Samples were stored on ice or at $4{ }^{\circ} \mathrm{C}$ until analyses could be performed. Swatches of new membranes used for controls were submerged in boiling nano-pure water for $10 \mathrm{~min}$, rinsed with nano-pure water and then stored in a sterile container at $4{ }^{\circ} \mathrm{C}$. Prior to analysis, they were rinsed again with nano-pure water.

For focus emission scanning electron microscopy (FSEM) of autopsied membranes, $1 \mathrm{~cm}^{2}$ samples were prepared as per the information in the following section on analytical methods.

During Phase 3 and 4 the membrane feed channel spacer was analyzed. A $4 \mathrm{~cm} \times 4 \mathrm{~cm}$ square was cut from the spacer mesh over the same areas where membrane swatches were cut with a sterile scalpel and the above processes followed.

\section{Analytical methods}

\section{Conductivity}

Conductivity was measured weekly in the feed, retentate and permeate streams. Permeate conductivity data were normalized by taking the ratio of the current measurement to the initial measurement $\left(C_{t} / C_{0}\right)$. In Phases 1 and 2, conductivity was measured with a Traceable $^{\circledR}$ automatic temperature compensating digital conductivity meter (Fisher Scientific, Cat \# 967053, www.fishersci.com) standardized by measuring the conductivity of $0.01 \mathrm{M} \mathrm{KCl}$ and determining a cell constant for the conductivity meter. Sample temperatures were adjusted to $25^{\circ} \mathrm{C}$. During Phases 3 and 4 , conductivity was directly measured with an Accumet AP65 portable conductivity meter (Fisher Scientific, Cat \# 13-636-AP65A) with an Accumet two cell conductivity probe 1.0 (Fisher Scientific, Cat \# 13-620-168).

\section{Adenosine triphosphate (ATP) luminescence}

ATP was monitored bi- or tri-weekly in the feed, retentate and permeate using the BacTiter-Glo ${ }^{\mathrm{TM}}$ Microbial Cell Viability Assay Kit (Promega, Cat G8230, www.promega.com) and a Lumitester C-110 luminometer (LuminUltra Technologies Ltd., New Brunswick, Canada). Undiluted samples were run in triplicate following a single tube method where $100 \mu \mathrm{l}$ of suspended reagent were added to $100 \mu \mathrm{l}$ of sample. Each tube was then shaken for $2 \mathrm{~s}$ and then incubated for $10 \mathrm{~min}$ before luminescence was recorded with the luminometer. A standard curve using triplicate samples of $10 \mathrm{mM}$ rATP (Promega, Cat \# P1132) serially diluted between $10^{-7} \mathrm{M}$ and $10^{-11} \mathrm{M}$ ATP and blanks of autoclaved nano-pure water was prepared each time the ATP analysis was performed. The same method was used for scraped membrane swatch samples.

\section{Heterotrophic plate counts (HPC)}

HPC were monitored bi- or tri-weekly in the feed, retentate, and permeate and in scraped membrane samples by diluting as needed in autoclaved nanopure water and spread plating triplicate samples on Difco ${ }^{\mathrm{TM}}$ R2A agar (BD, Franklin Lakes, NJ, USA, Cat \# 218261) with incubation at $28^{\circ} \mathrm{C}$ for seven days. During autopsies in Phase 3 and 4, a portion of the scraped sample was homogenized for a comparison study. Samples were prepared using a homogenizer (IKA, Model \# T25S1, Staufen im Breisgau, Germany) for $30 \mathrm{~s}$ at $20,500 \mathrm{rpm}$. Between samples, the homogenization probe was cleaned by a $70 \%$ ethanol solution and sterile water. There was no statistical difference between the two analyses (data not shown).

\section{Direct cell counts}

Direct cell counts were performed weekly on the feed and biweekly on the retentate and on scraped membrane autopsy samples. In most cases, retentate counts were below detection. For feed waters, $5 \mathrm{ml}$ of undiluted sample were stained with LIVE/DEAD ${ }^{\circledR}$ BacLight $^{\mathrm{TM}}$ Bacterial Viability Kit (Life Technologies, Cat \# L7012, www.lifetechnologies.com) stains using $500 \mu \mathrm{l}$ of a 1:150 or 1:300 stain solution. Retentate (2. $5 \mathrm{ml}$ undiluted) and scraped membrane samples $(2.5 \mathrm{ml}$ diluted) were stained with $500 \mu \mathrm{l}$ of a 1:300 stain solution. Samples were incubated for $45 \mathrm{~min}$ in the dark and then filtered onto a $25 \mathrm{~mm} 0.2 \mu \mathrm{m}$ pore size black polycarbonate membranes (Maine Manufacturing LLC, Cat \# 1215609, Sanford, ME, USA) and observed by fluorescence microscopy using a Nikon Eclipse E800 and $100 \times$ Nikon oil emersion lens (Brighton, MI, USA). For Phase 1 and 2, 20 frames of reference per sample were analyzed. For Phases 3 and 4 the imaging equipment was upgraded and 35 frames of reference were captured to ensure the same area was being analyzed. For each frame of reference, separate images for live (FITC filter at an excitation wavelength of $495 \mathrm{~nm}$ ) or dead cells/cells with damaged membranes (TRITC filter at an excitation wavelength of $552 \mathrm{~nm}$ ) were captured using the software MetaVue ${ }^{\circledR}$ (https://www. 
moleculardevices.com/products/cellular-imaging-systems/ acquisition-and-analysis-software/metamorph-microscopy). The two images were combined using the MetaMorph $^{\circledR}$ color combine function. The color threshold function in MetaMorph ${ }^{\circledR}$ was used to define cell areas brighter than 55 on a scale from 0 to 255, and cells with areas between 5 and 350 pixels were counted by the software.

\section{Cell clumping}

The color combined microscope images from the direct counts were also used to determine the extent of cell clumping in the retentate. The MetaMorph ${ }^{\circledR}$ software determined the pixel area of all thresholded cell and clump areas $>5$ pixels, the area data exported to MS Excel $^{\circledR} 2010$ (https://www.microsoft.com/en-us/p/excel2016/cfq7ttc0k5f3?activetab=pivot\%3aoverviewtab) and an average cell area was determined by finding the arithmetic average of cells with pixel areas between 5 and 350 . The measured cell and clump areas were divided by the calculated average to determine the approximate number of cells per clump. Clump data were analyzed (1) to determine whether clump sizes increased over time, (2) to compare the number of cells in certain clump size ranges and single cells to the total number of cells in a sample, and (3) to monitor the concentration of clumps $>5$ cells over time. Total occurrences were calculated by adding the numbers of single cells, clumps with areas equal to cell numbers between 2 and 10 and clumps with areas exceeding 10 cells.

\section{Sessile carbohydrates and protein}

The phenol-sulfuric acid method was used to determine the concentration of sessile carbohydrates, with a standard curve created using D-glucose (Fisher Scientific, Cat \# D16-500). Sessile protein was determined using a Coomassie Plus (Bradford) Assay Kit (Pierce Biotechnology, Cat \# 23236, www.thermoscientific.com/pierce). All samples and standards were run in triplicate.

\section{Focus emission scanning electron microscopy (FESEM)}

FESEM was used to visualize the degree and type of foulant on the membrane surface. A $1 \mathrm{~cm} \times 1 \mathrm{~cm}$ swatch was carefully cut from the membrane and placed in a sterile Petri dish. Samples were air dried and stored at $4{ }^{\circ} \mathrm{C}$. Just prior to analysis, samples were sputter coated (Emitech, Model \# K575X, www. quorumtech.com) with an iridium target. Images were acquired at $500 \times$ and $4,000 \times$ magnification and captured with a Zeiss Surpa 55VP using secondary electron imaging (SEI).

\section{Cryo sectioning}

Cryo sectioning was used to analyze the thickness of the fouling layer on the membrane surface. A $1 \mathrm{~cm}$ $\times 1 \mathrm{~cm}$ swatch was flooded with LIVE/DEAD ${ }^{\circledR}$ BacLight $^{\mathrm{TM}}$ stain. Swatches were incubated for $1 \mathrm{~h}$ in the dark, rinsed, and placed on dry filter paper.

Tissue Tek OCT compound (Sakura Finetek, Cat \# 4583, Torrance, CA, USA) and dry ice were used to encapsulate the feedwater side. The support layer of the membrane was then removed and the backside covered with the OCT compound and allowed to freeze. Cryo sectioning was performed with a Leica CM1850 cryostat (Lieca Inc., Buffalo Grove, IL USA).

Five $\mu \mathrm{m}$ slices were mounted on Superfrost ${ }^{\mathrm{TM}}$ Plus slides (VWR, Cat \# 48311-703, http://us.vwr.com). Sections were imaged using a Nikon Eclipse E800 and a $20 \times$ Nikon or $40 \times$ Nikon lenses. Images were captured using the software MetaVue ${ }^{\circledR}$ for fluorescence image capturing. Image analysis was performed using MetaMorph $^{\circledR}$ image analysis software. Image pixels were calibrated to actual distance in $\mu \mathrm{m}$ using the calibrate distances function under the measure menu. Distance calibrations were performed earlier by imaging a micrometer under the relevant objective magnifications and measuring the number of pixels in $1 \mu \mathrm{m}$.

\section{Statistical analysis}

Operational data for all the phases were combined and graphed so promising parameters for the non-destructive assessment of biofouling could be determined. The operational data were truncated at the point where membrane failure occurred so that any trailing data would not impact the models. On certain datasets, $\log _{10}$ transforms were performed to linearize the data, ie retentate cell clumping and HPCs. Statistical models were run using Minitab ${ }^{\mathrm{TM}}$ v. 17 (http://www.minitab. com/en-US/) to determine whether the values in measured operational parameters were significantly different between feed types.

For each separate operational parameter, an ANOVA modeled trans-membrane pressure drop as the response with feed type as a fixed effect, the operational parameter as a covariate (after log-transforming in the case of retentate cell clumping and HPCs), and the two-way interaction. Experimental reactor was a random effect to account for the repeated 
technical replicates from each of the three reactors for each feed type. Experimental replicates for each condition (Phase 4) were also included in the statistical analysis. Residual and normal probability plots were used to identify outliers and assess the constant variance, normality and linearity assumptions of the ANOVA. Statistical significance was claimed for $p$ values $<0.05$.

\section{Results}

\section{Time to membrane failure}

The total run time for Phase 1 (first 49 days had $2 \mathrm{mgl}^{-1}$ organic carbon that was increased to $10 \mathrm{mgl}^{-1}$ organic carbon and a constant $500 \mathrm{mgl}^{-1}$ inorganic feed) was 94 days with an accumulated passage of 2,8001 of feed water. Phase 2 used baseline $\left(150 \mathrm{mgl}^{-1}\right)$ inorganic concentrations and $10 \mathrm{mgl}^{-1}$ of organics to emphasize biofouling, with failure at 88 days and 2,6001 feed water passage. Phase 3 used no added organics and $500 \mathrm{mgl}^{-1}$ of inorganics, with membrane failure noted at 173 days and 5,1001 passage of feed water. In Phase 4 where lines were run with inorganics alone, combined organics and inorganics, and organics alone, the times to failure were 110 days and 3,400 1; 56 days and 1,700 l; and 81 days and 2,4001, respectively. Calculations were made to compare time to failure and feed water passage between replicate experimental conditions. The most complicated situation was the combined organic and inorganic experiments (Phases 1 and 4 ) because the initial organics concentration $\left(2 \mathrm{mgl}^{-1}\right)$ in Phase I was $20 \%$ of the final organics concentration $\left(10 \mathrm{mgl}^{-1}\right)$. One fifth the operational time under the lower organics concentration was 10 days with 3001 of feed water passed. Adding these calculated values to the operational time at $10 \mathrm{mgl}^{-1}$ organics results in an operational timeframe of 55 days and 1,600 of feed water passed which is very similar to the combined loading line of Phase 4. For organics only, failure in Phase 2 was comparable to the same condition in Phase 4. This indicates that the general rate of biofouling in the combined and organics only loading was very similar between the phases. However, this similarity did not extend to the membranes with low organics and high inorganics; there were differences between the Phase 3 and replicate line in Phase 4 in both time to failure and feed water. Overall, membranes with combined loading had the shortest lifespans followed by organic loading and then inorganic loading.

\section{Membrane autopsies}

The goal of the project was to determine non-destructive method(s) to assess biofouling. To achieve this goal, it was critical to assess the presence of biofouling on membrane surfaces via membrane autopsies.

Because of the experimental design, it was only possible to compare autopsy results for all three feed loading conditions at the final autopsy point (after membrane failure). Indicators of biofouling (ATP, HPC, sessile carbohydrates and protein) trended higher in membranes subjected to combined and organic loading compared to those subjected to inorganics only (data not shown). However, there was no correlation between these measurements; if a membrane swatch had the highest recorded sessile ATP it did not necessarily have the highest sessile protein, HPCs, or direct counts (data not shown). There was a progression of the biological indicators in Phase 2 (organics only) between the first autopsy time point $(\sim 1 / 3$ system life span) and the second autopsy time point ( $\sim 2 / 3$ system life span). Sessile ATP, protein, and carbohydrates increased by two orders of magnitude between these time points and FESEM images taken during the second autopsy showed concurrent covering of the membrane surface by biofilm (images not shown).

The most revealing autopsy data for biofouling across all experiments was ATP (Figure 2). Phases 1-3 had triplicate membrane units with combined, organics only and inorganics only as feed waters. ATP was highest on the organics only membrane swatches, the combined treatment had the next highest level, and concentrations were at the level of detection for the inorganics only membranes. For Phase 4, each unit was run with one of the three influent conditions and ATP measured on the membranes and spacers. The trends seen in the earlier experiments were reproducible, although the actual concentrations were not. As expected, the ATP data support the premise that organic loading promotes biofouling.

Representative images from Phase 4 also illustrate the development of biofouling (Figure 3). The surface of the membrane fed with inorganics only had evidence of mineral solids. This was supported by testing for calcium carbonate using hydrochloric acid with the production of carbon dioxide gas bubbles. The average thickness of the scale was $23 \mu \mathrm{m}_{ \pm} 6 \mu \mathrm{m}$. The combined feedwater membrane had inorganic crystals coated with biological material resembling cells and extracellular biofilm matrix material. However, cryosectioning of this membrane was unsuccessful (separation of the membrane and fouling layer) and thickness could not be measured. The organics only 


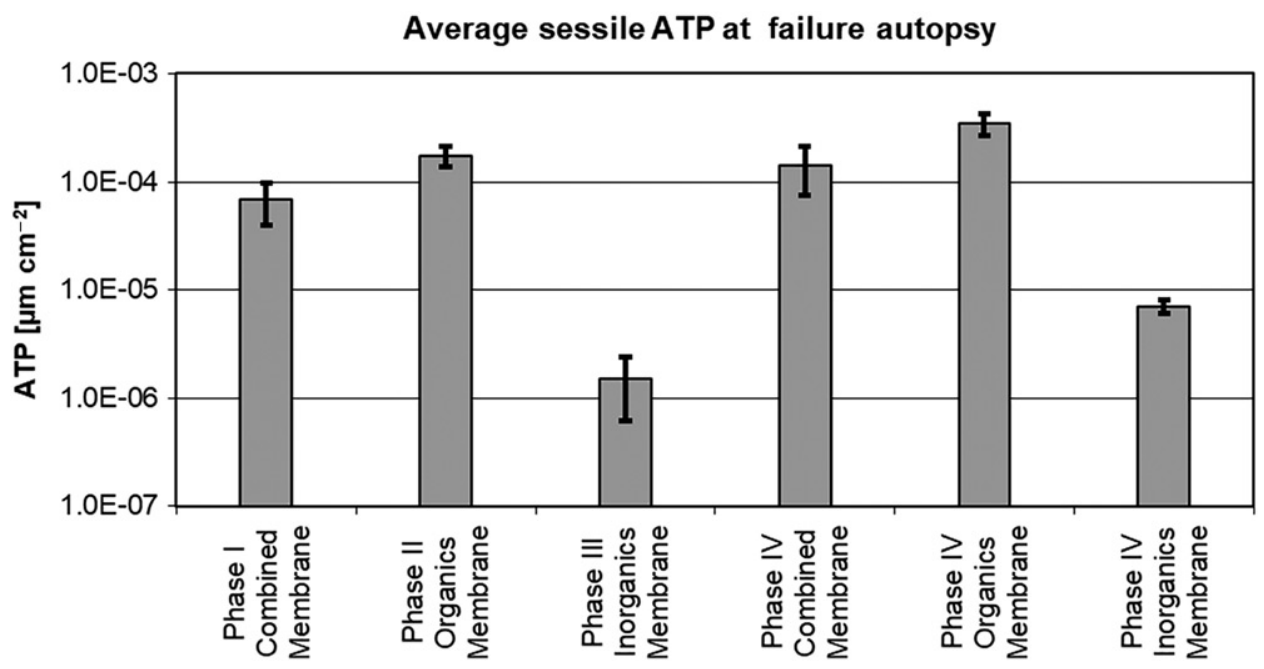

Figure 2. ATP on membrane surfaces during autopsy for organics only, combined organics/inorganics, and inorganics only feedwaters.

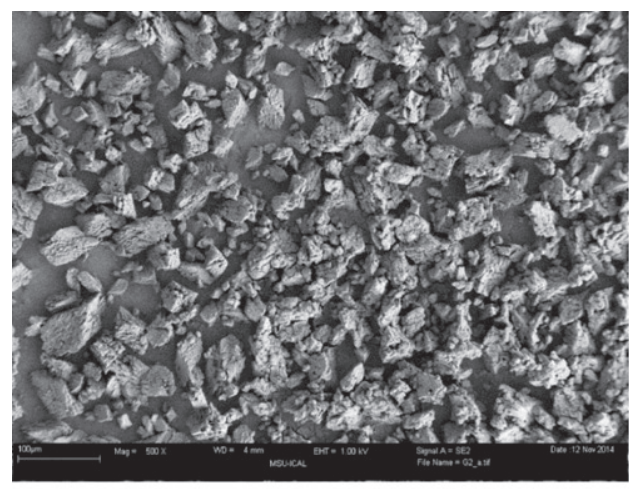

(A) Inorganics only

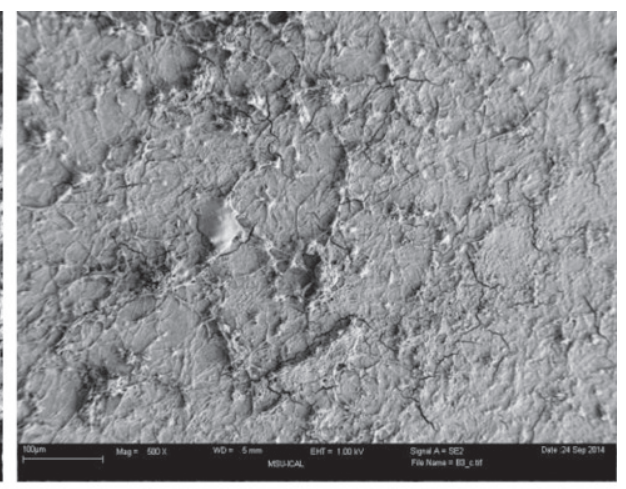

(B) Combined organics and inorganics

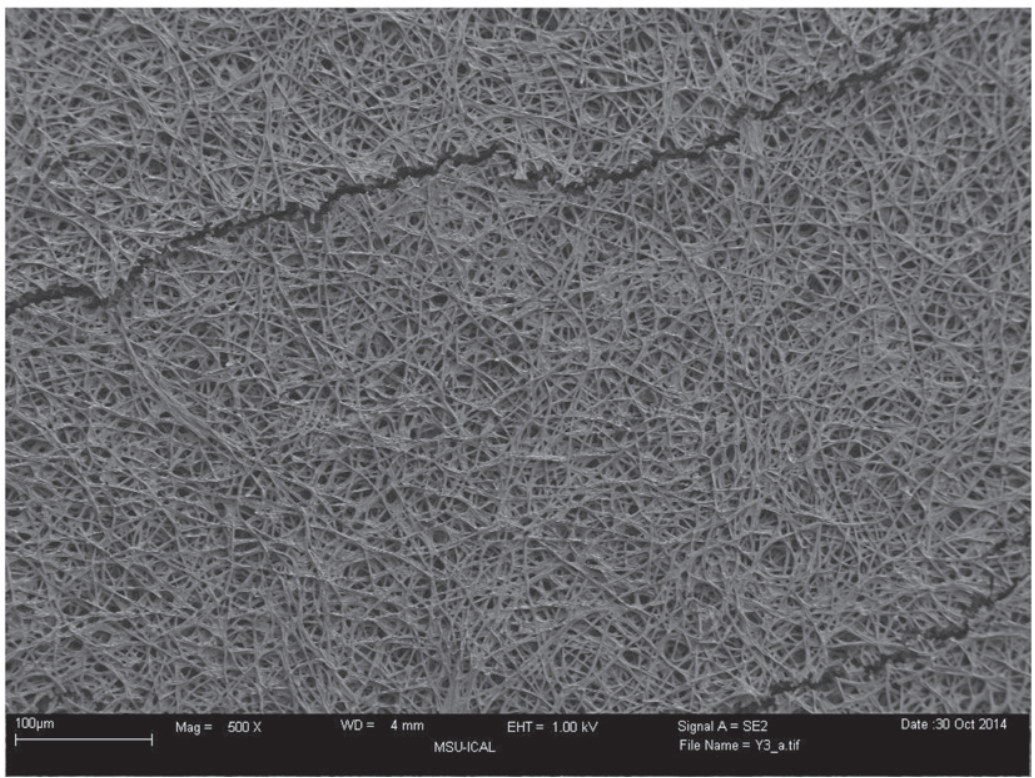

(C) Organics only

Figure 3. Fouling after membrane failure at $500 \times$ magnification using FSEM. Times of operation to failure were 110 days (A), 61 days (B) and 95 days (C). 
Table 3. Statistical analysis: $p$-values.

Significantly different: $p$-value $\leq 0.05$

Response: trans-membrane pressure drop

\begin{tabular}{lccc} 
& Combined vs inorganics $p$-value & Combined vs organics $p$-value & Inorganics vs organics $p$-value \\
\cline { 2 - 4 } Log $_{10}$ retentate cell clumping: clumps $>5$ cells & $0.000^{*}$ & 0.477 & 0.000 \\
Permeate flux: $/ F_{0}$ & 0.000 & 0.018 & 0.000 \\
Permeate conductivity: $C / C_{0}$ & 0.002 & 0.562 & 0.001 \\
Change in feed channel pressure drop & 0.387 & 0.197 & 0.104 \\
Difference between retentate and feed ATP & 0.633 & 0.060 & 0.000 \\
Difference between retentate and feed log IPC $_{10} \mathrm{HPC}$ & 0.003 & 0.293 & 0.000 \\
Difference between retentate and feed direct counts & 0.888 & 0.333 & 0.885
\end{tabular}

0.888

Response: permeate $F / F_{0}$

Combined vs inorganics $p$-value Combined vs organics $p$-value Inorganics vs organics $p$-value Permeate $\mathrm{C} / \mathrm{C}_{0}$ 0.000 0.010 0.000

*Zero values reported to three decimal places.

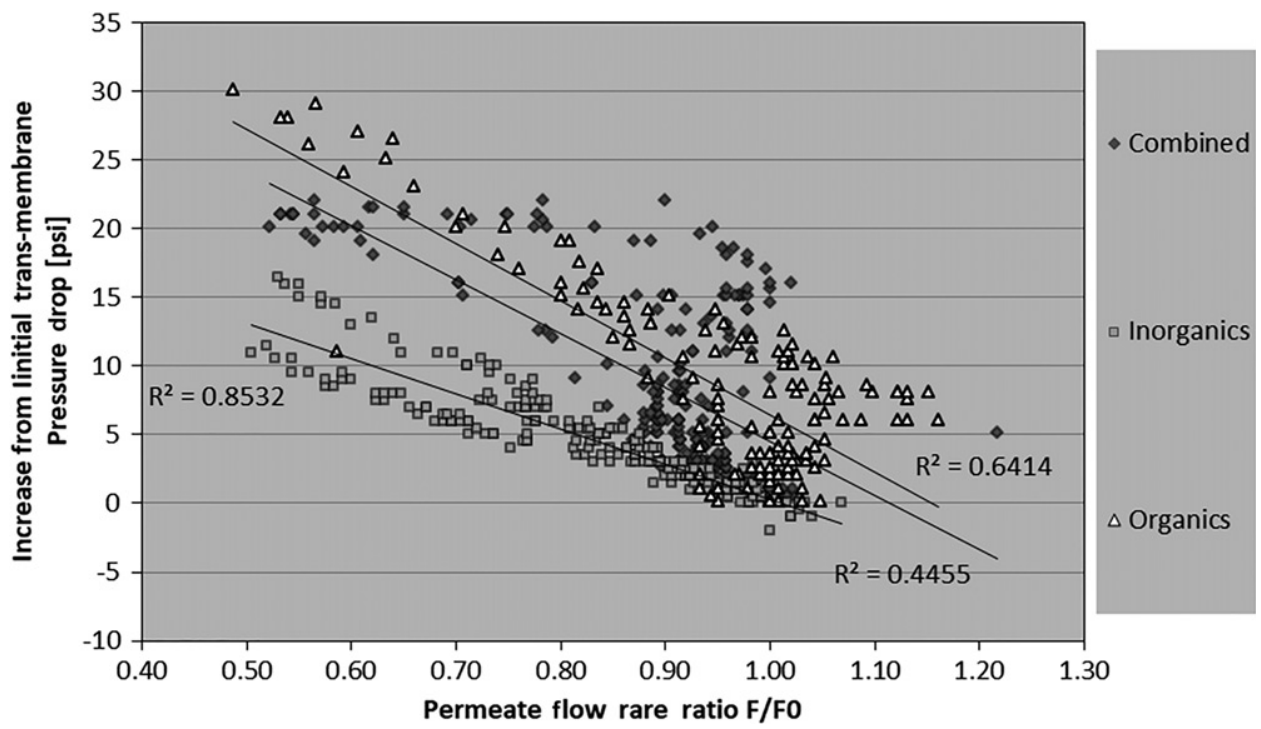

Figure 4. Increase in trans-membrane pressure drop vs permeate flow rate ratio. Membranes loaded with inorganics showed a linear decline in flux unlike the membranes with biofouling (combined and organics loaded).

surfaces had similar structures minus the crystals with a visible biofilm. The average thickness of the fouling layer was $40 \mu \mathrm{m} \pm 14 \mu \mathrm{m}$.

\section{Analysis of retentate parameters}

Because the goal was to determine non-destructive measurements related to biofouling, the research focused on the analysis of the feed water, retentate, and permeate. Statistical analysis was performed on the data from the four separate experiments to determine the parameters that correlated with biofouling as determined by endpoint destructive membrane autopsies (Table 3). Although many assays were used, several did not provide useful information and were not uniquely associated with biofouling. These include pressure drop, several retentate biological parameters (protein, heterotrophic plate counts, total cell counts, ATP), and changes in total organic carbon from feed water to retentate. Therefore, these data are not included in the following discussion.
Ideally, there should be at least two measurable changes that can be used in concert to determine if biofouling is occurring. Parameters that were deemed important were changes in permeate flow and conductivity and the presence of cell clumps in the retentate. However, these parameters were not indicative of biofouling early on; divergent trends in these values with respect to feed type did not occur until 2/3 the maximum trans-membrane pressure drop was achieved. Further discussion of the two valuable parameters is detailed below.

\section{Ratios of permeate flow and conductivity ( $F / F_{0}$ and $\left.C / C_{0}\right)$}

ANOVA analysis (slopes of the regression lines) concluded that the ratio of permeate flow over the initial permeate flow $\left(\mathrm{F} / \mathrm{F}_{0}\right)$ and feed type interaction was significantly different based on feed type. Membranes loaded with inorganics only had a linear decline in 


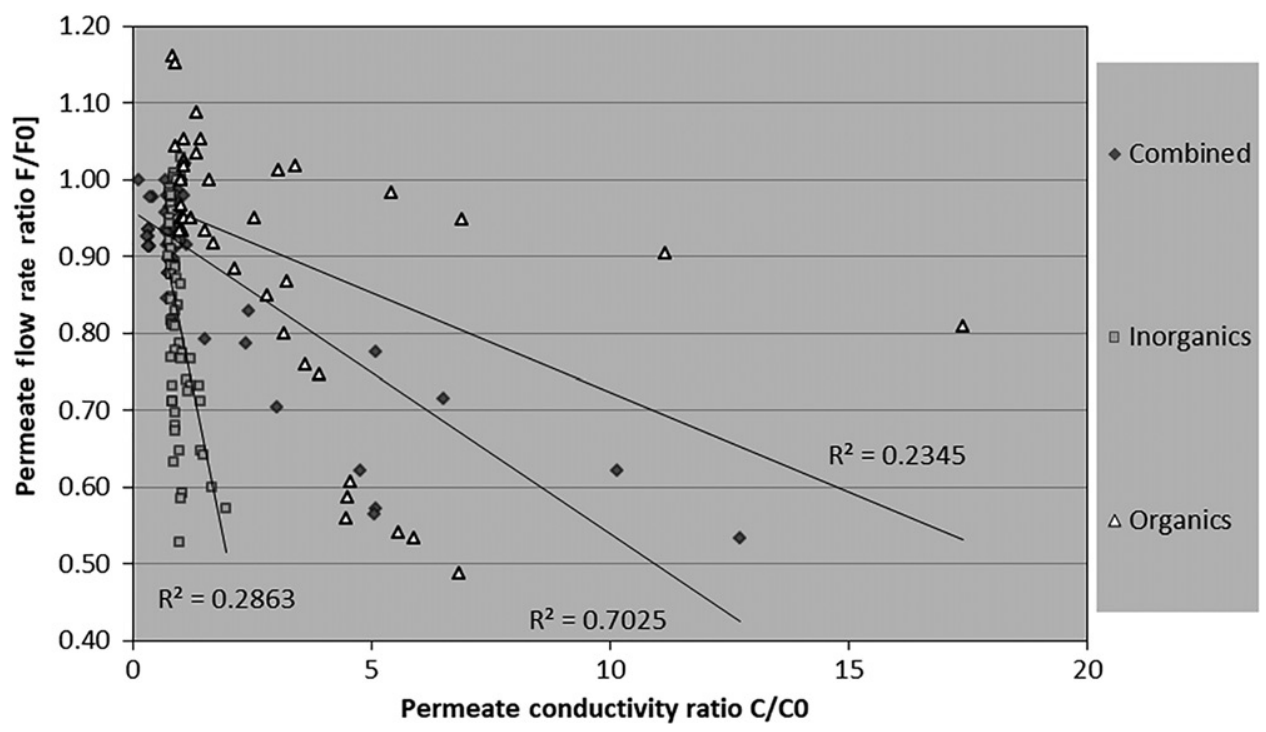

Figure 5. Permeate flow ratio vs Permeate conductivity ratio.

flux, unlike the membranes with biofouling (combined and organics loaded) (Figure 4). A similar relationship was seen with the ratio of permeate conductivity to feed water conductivity $\left(\mathrm{C} / \mathrm{C}_{0}\right)$ (data not shown). Membranes with biofouling experienced large increases in permeate conductivity compared to membranes that were inorganically fouled. The interaction (slope of the regression line) was significantly different between the combined and inorganic feed types and the organic and inorganic feed types and no significance was noted between the combined and organics feed types. Therefore, the permeate conductivity ratio was also correlated with biofouling in the cases of combined and organics loading.

Statistical models were also generated with the same fixed and nested random effects to compare the permeate $\mathrm{F} / \mathrm{F}_{0}$ ratio to the permeate $\mathrm{C} / \mathrm{C}_{0}$ ratio (Figure 5). The covariate was permeate $\mathrm{C} / \mathrm{C}_{0}$ and the interaction between covariate and feed type was treated as the most important parameter of the model. The only difference was that permeate $\mathrm{F} / \mathrm{F}_{0}$ was the response instead of the increase in transmembrane pressure drop. All interactions were significantly different based on feed type, with the membranes suffering from biofouling experiencing a rise in permeate conductivity as flux decreased. Therefore, in addition to the individual correlations with flux and conductivity and biofouling, a combined analysis also supported this interaction.

\section{Retentate cell clumps}

Ideally there should be a biological parameter associated with biofouling. The number of cell clumps $(>5$ cells/clump) in the retentate, which is likely to be related to detached biofilm, was pursued as a potential biofouling indicator. With Phase 1 (combined loading) and the organically loaded membrane of Phase 4, clump values approached or surpassed 50,000 clumps $\mathrm{ml}^{-1}$. The averaged maximum clump number during advanced biofouling (last $1 / 3$ of system lifespan) was around 40,000 clumps $\mathrm{ml}^{-1}$. Clump numbers in Phase 2 (organics only) were lower with a maximum observed value of 25,000 clumps $\mathrm{ml}^{-1}$. For the membranes only experiencing inorganic fouling in Phase 3 and the combined loaded membrane of Phase 4 , values generally were $<5,000$ clumps $\mathrm{ml}^{-1}$.

The $\log _{10}$ transforms of the retentate cell clumping data linearized the data which was followed by application of a statistical model. Statistical analysis indicated that the interaction between $\log _{10}$ retentate cell clumps ( $>5$ cells per clump) and feed type (slope of the regression line) was significantly different between the combined and inorganic feed types and the organic and inorganic feed types. In membranes suffering from biofouling, increased retentate cell clump numbers were observed at high trans-membrane pressures (Figure 6). No significant difference was noted between the combined and organics feed types. As described above, autopsy data also indicated that biofouling occurred in both the combined and organics loading cases.

\section{Discussion}

It was originally thought that feed channel pressure drop would be a key indicator of biofouling since extensive research by Vrouwenvelder et al. (2011a) 


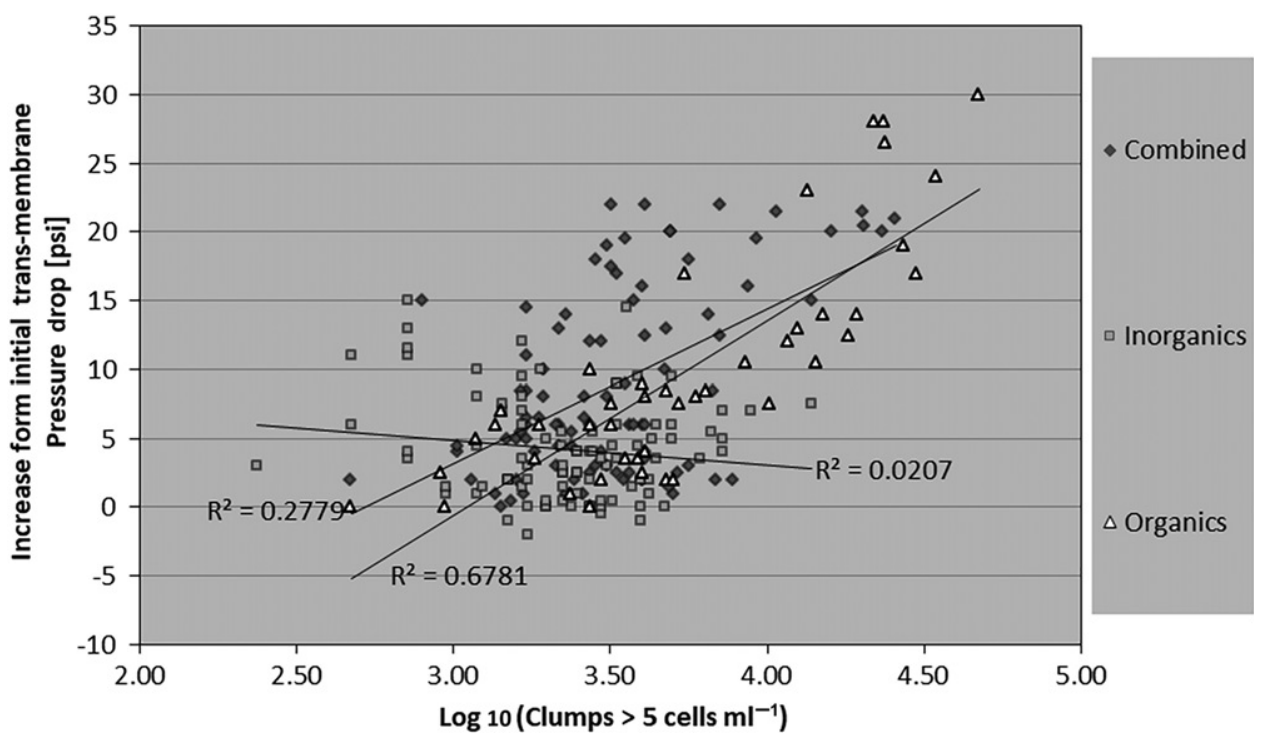

Figure 6. Increase in trans-membrane pressure vs retentate cell clumping. In membranes with biofouling, large retentate cell clumping values were observed at high trans-membrane pressures.

linked the growth of biofilm on the membrane's feed channel spacer to an increased feed channel pressure drop. However, they also noted that feed channel pressure drop can be seen in other fouling cases. In the statistical analysis, interactions between the feed type and feed channel pressure drop were not significantly different between the feed types, indicating that the feed channel pressure drops were independent of the type of fouling. The experimental results suggested that the real difference may not be in the degree to which the feed channel pressure drop increased with respect to trans-membrane pressure drop but in the magnitude of the feed channel pressure drop. Phase 4 combined and organics loading feed channel pressure drops had a maximum value of $9.65 \times 10^{4} \mathrm{~Pa}$ and $8.96 \times 10^{4} \mathrm{~Pa}$, respectively. This is three times greater than the maximum observed feed channel pressure drop $\left(3.45 \times 10^{4} \mathrm{~Pa}\right)$ associated with inorganics only loading.

With the inability for feed channel pressure drop to predict biofouling, the focus shifted to other parameters. Analysis of the data collected over the four experimental phases suggested that three statistically significant, nondestructive parameters could be used to assess biofouling, these being permeate $\mathrm{F} / \mathrm{F}_{0}$, permeate $\mathrm{C} / \mathrm{C}_{0}$ and retentate cell clumping. These parameters were related to the presence of biofouling evaluated in the destructive membrane autopsies. Vrouwenvelder et al. (2011a) extensively used autopsies to correlate sessile ATP with various operational parameters and to assess the degree of biofouling. Biofilm accumulation was confirmed by autopsy analysis of the membranes, with at least an order of magnitude more sessile ATP on biofouled membrane surfaces than on those experiencing inorganic fouling.

Permeate flow rates decreased differently throughout system lifespan depending on the type of fouling. Membrane lines suffering from inorganic fouling had a gradual and linear decrease in flux, which is consistent with Uchymiak et al. (2009) where linear flux decline with respect to surface coverage of scale was seen during the development of the ex situ scale observation detector (EXSOD). An increase in inorganic foulants seen in FESEM images taken during Phase 3 (inorganics only) corresponded with a linear decline in flux. In addition, inorganically fouled membranes failed due to an inability to meet permeate production (volume) thresholds, whereas membranes with biofouling failed due to an inability to meet permeate quality thresholds. In these cases, permeate production remained constant for the initial $2 / 3$ of the membranes' lifespan with a subsequent breakpoint with a substantial flux decline. Similar operational characteristics were noted in studies done by Vrouwenvelder et al. (2011a) where they observed that biomass accumulation in membrane modules increased feed channel pressure drop before the flux declined.

In biofouling cases, a substantial decrease in flux may be explained by increased biofouling of the feed channel spacer and membrane surface. Biofilm EPS increases hydraulic resistance and therefore decreases flux (Herzberg and Elimelech 2007). Ho et al. (2016) 
also noted that there were two stages in biofilm formation on membranes, characterized by the accumulation of cells followed by the production of EPS. Sessile feed spacer ATP data taken during Phase 4 indicates a high level of ATP on the feed channel spacers of the combined and organics lines. Research with NMR has shown that biofilm growth on the feed channel spacer results in a multitude of negative operating consequences, such as disruption of flow field homogeneity, dead zones (no fluid flow), development of preferential flow paths and back flow (Graf von der Schulenburg et al. 2008; Pintelon et al. 2010; Vrouwenvelder et al. 2011a; van Loosdrecht et al. 2012). Modeling by Radu et al. (2015) suggests that accelerated flux decline may be the result of combined fouling in feed channels with spacers as the result of mineralization in biofilms, but noted that this was likely related to the composition of the feedwater. Regardless, biofilm formation was important for the loss of productivity.

In membranes with biofouling, greater increases in permeate conductivity were observed compared to inorganic fouling only. Research has shown that upon the development of a biofilm, an increase in salt concentration near the membrane surface led to increased salt transport across the membrane along with an elevated trans-membrane osmotic pressure that led to a decreased flux (Herzberg and Elimelech 2007). A decrease in permeate flux then further increased the permeate salt concentration. Biofouling has a twopronged, negative effect on permeate conductivity: it increases the salt concentration near the membrane surface, which increases salt transport across the membrane, and the decreased permeate flux then leads to a concentration effect of the passed salts. In a set of experiments with a pure culture, compact biofilms on RO systems resulted in an increase in osmotic pressure and hydraulic resistance (Kwan et al. 2015).

Cell clumping in the retentate was chosen as a potential indicator of biofouling due to the known phenomenon of cell release from biofilms. As the biofilm grows on the membrane and other parts of the system, detachment and sloughing occurs. According to Flemming (1997), biofilm detachment should become more prevalent as the biofilm nears the plateau phase. Cell clumping analysis was performed using a procedure similar to that outlined in prior research (Wilson et al. 2004; Behnke et al. 2011). A model predicting the rate of detachment events of a certain size was created through clumping analysis in Wilson et al. (2004). Furthermore, in Behnke et al.
(2011), clump sizes and frequency of occurrence were successfully measured in biofouled tube reactors and only $33 \%$ of the total effluent cells in biofouled tube reactors existed as single cells. Findings from Dixon et al. (2012) in full scale membrane plants further support the use of clumping analysis since they attributed cell clumping to some of the error in their flow cytometry analysis. In the current study, the prevalence of cell clumps in the retentate was correlated to the actual state of membrane biofouling determined through autopsies. Additionally, $\sim 45 \%$ of the total cells in the system existed as single cells and the rest were present in clumps.

This research using feedwater that accelerated fouling highlighted a combination of promising, simple methods to non-destructively assess biofouling of RO membranes. High permeate conductivity and nonlinear trends in the permeate flow ratio occurred only in membranes with biofouling. When combined with an analysis of cell clumps in the retentate, the data were indicative of biofouling. These methods rely on trend analyses, requiring that data be collected at different operational time points. A combination of these methods provides an inexpensive predictor of biofouling.

\section{Acknowledgements}

The research was funded by Unilever Safety and Environmental Assurance Centre and provided a MSc studentship to Stephen Markwardt. Special thanks are due to all the staff at the Center for Biofilm Engineering for their help and support throughout this project. Dr Al Parker is acknowledged for his assistance with statistics.

\section{Disclosure statement}

Authors Markwardt, Ronnie and Camper will gain no financial benefit from direct applications of this research.

\section{References}

Al-Juboori RA, Yusaf T. 2012. Biofouling in RO system: mechanisms, monitoring and controlling. Desalination. 302:1-23. doi:10.1016/j.desal.2012.06.016

Antony A, Blackbeard J, Leslie G. 2012. Removal efficiency and integrity monitoring techniques for virus removal by membrane processes. Crit Rev Envron Sci Technol. 42:891-933. doi:10.1080/10643389.2011.556539

Behnke S, Parker AE, Woodall D, Camper AK. 2011. Comparing the chlorine disinfection of detached biofilm clusters with those of sessile biofilms and planktonic cells in single- and dual-species cultures. Appl Environ Microbiol. 77:7176-7184. doi:10.1128/AEM.05514-11 
Dixon MB, Lasslett S, Pelekani C. 2012. Destructive and non-destructive methods for biofouling analysis investigated at the Adelaide Desalination Pilot Plant. Desalination. 296:61-68. doi:10.1016/j.desal.2012.04.004

Farhat NM, Staal M, Siddiqui A, Borisov SM, Bucs SS, Vrouwendvelder JS. 2015. Early non-destructive biofoulng detection and spatial distribution: application of oxygen sensing optodes. Water Res. 83:10-20. doi:10.1016/j.watres.2015.06.015

Flemming HC. 1997. Reverse osmosis membrane biofouling. Exp Therm Fluid Sci. 14:382-391. doi:10.1016/ S0894-1777(96)00140-9

Fridjonsson EO, Vogt SJ, Vrowenvelder JS, Johns ML. 2015. Early non-destructive biofouling detectin in sprial wound RO membranes using a mobile earth's field NMR. J Membr Sci. 489:227-236. doi:10.1016/j.memsci.2015.03.088

Graf von der Schulenburg DA, Vrouwenvelder JS, Creber SA, van Loosdrecht MCM, Johns ML. 2008. Nuclear magnetic resonance microscopy studies of membrane biofouling. J Membr Sci. 323:37-44. doi:10.1016/j.mem sci.2008.06.012

Herzberg M, Elimelech M. 2007. Biofouling of reverse osmosis membranes: role of biofilm-enhanced osmotic pressure. J Membr Sci. 295:11-20. doi:10.1016/j.mem sci.2007.02.024

Ho MS, Low JH, Sim LN, Webster RD, Rice SA, Fane AG, Coster HGL. 2016. Monitoring of biofouling on reverse osmosis membranes: detection and mechanistic study using electrical impedence microscopy. J Membr Sci. 518:229-242. doi:10.1016/j.memsci.2016.06.043

Huang S, Voutchkov N, Jiang SC. 2013. Investigation of environmental influences on membrane biofouling in a Southern California desalination pilot plant. Desalination. 39:1-9.

Hwang S-N, Choi W, Lim H, Choi J, Kim H, Chang IS. 2012. Fluorescence spectrum-based biofouling prediction method for RO membrane systems. Desalination Water Treat. 43:238-245. doi:10.1080/19443994.2012.672178

Kappelhof J, Vrouwenvelder JS, Schaap M, Kruithof JC, van der Kooij D, Schippers JC. 2003. An in situ biofouling monitor for membrane system. Membr Drink Ind Water Prod. Iii:205-210.

Kavanagh JM, Hussain S, Chilcott TC, Coster HGL. 2009. Fouling of reverse osmosis membranes using electrical impedance spectroscopy: measurements and simulations. Desalination. 236:187-193. doi:10.1016/j.desal.2007.10.066

Kögler M, Zhang B, Cui L, Shi Y, Yliperttula M, Laaksonen T, Viitala T, Zhang K. 2016. Real-time Raman based approach for identification of biofouling. Sens Actuators B Chem. 230:411-421. doi:10.1016/j.snb.2016.02.079

Komlenic R. 2010. Biofouling: rethinking the causes of membrane biofouling. Filtr Sep. 7:26-28.

Kwan SE, Bar-Zeev E, Elimelech M. 2015. Biofouling in forward osmosis and reverse osmosis: measurements and mechanisms. J Membr Sci. 493:703-708. doi:10.1016/ j.memsci.2015.07.027

Mia B, Eaton CL, Kim J-H, Colvin CK, Loziere JC, Marin BJ. 2004. Removal of biological and non-biological viral surrogates by spiral-wound reverse osmosis membrane elements with intact and compromised integrity. Water Res. 38:3821-3832. doi:10.1016/j.watres.2004.07.004

Pandey SR, Jegatheesan V, Baskaran K, Shu L. 2012. Fouling in reverse osmosis (RO) membranes in water recovery from secondary effluent: a review. Rev Environ Sci Biotech. 11:125-145. doi:10.1007/s11157-012-9272-0

Pintelon TRR, Creber SA, von der Schulenburg DAG, Johns ML. 2010. Validation of 3D simulations of reverse osmosis membrane biofouling. Biotechnol. Bioeng. 106:677-689. doi:10.1002/bit.22717

Radu AI, Bergerff L, van Loosdrecht MCM, Picioreanu C. 2015. Combined biofouling and scaling in membrane feed channels: a new modeling approach. J Bioadhesion Biofilm Res. 31:83-100. doi:10.1080/08927014.2014.996750

Sim LN, Wang ZJ, Gu J, Coster HGL, Fane AG. 2013. Detection of reverse osmosis membrane fouling with silica, bovine serum albumin and their mixture using in-situ electrical impedance spectroscopy. J Membr Sci. 443:45-53. doi:10.1016/j.memsci.2013.04.047

Tay KG, Song LF. 2005. A more effective method for fouling characterization in a full-scale reverse osmosis process. Desalination. 177:95-107. doi:10.1016/j. desal.2004.11.017

Uchymiak M, Bartman AR, Daltrophe N, Weissman M, Gilron J, Christofides PD, Kaiser WJ, Cohen Y. 2009. Brackish water reverse osmosis (BWRO) operation in feed flow reversal mode using an ex situ scale observation detector (EXSOD). J Membr Sci. 341:60-66. doi:10.1016/j.memsci.2009.05.039

van Loosdrecht MCM, Bereschenko L, Radu A, Kruithof JC, Picioreanu C, Johns ML, Vrouwenvelder JS. 2012. New approaches to characterizing and understanding biofouling of spiral wound membrane systems. Water Sci Technol. 66:88-94. doi:10.2166/wst.2012.096

Vrouwenvelder JS, Kruithof J, van Loosdrecht MCM. 2011a. Biofouling of spiral wound membrane systems. IWA Publishing.

Vrouwenvelder JS, van der Kooij D. 2001. Diagnosis, prediction and prevention of biofouling of NF and RO membranes. Desalination. 139:65-71. doi:10.1016/S00119164(01)00295-8

Vrouwenvelder J, van Loosdrecht MCM, Kruithof JC. 2011b. Early warning of biofouling in spiral wound nanofiltration and reverse osmosis membranes. Desalination. 265:206-212. doi:10.1016/j.desal.2010.07.053

West S, Wagner M, Engelke C, Horn H. 2016. Optical coherence tomography for the in situ three-dimensional visualization and quantification of feed spacer channel fouling in reverse osmosis membrane modules. J Membrane Sci. 498:345-352. doi:10.1016/j.memsci.2015.09.047

Wilson S, Hamilton MA, Hamilton GC, Schumann MR, Stoodley PS. 2004. Statistical quantification of detachment rates and size distributions of cell clumps from wild-type (PAO1) and cell signaling mutant (JP1) Pseudomonas aeruginosa biofilms. Appl Environ Microbiol. 70: 5847-5852. doi:10.1128/AEM.70.10.5847-5852.2004 